\title{
Circulação ou oligarquização? Uma radiografia das composições partidárias em Goiás ${ }^{1}$
}

\author{
José Carlos de Oliveira Junior ${ }^{2}$ \\ Recebido em março de 2020 \\ Aceito em junho de 2020
}

\section{RESUMO}

Esse artigo tem como foco o estudo sobre a circulação das elites partidárias na Composição da Executiva Estadual de quatro partidos políticos do Estado de Goiás. Para tanto, se faz uma discussão teórica sobre a Teoria das Elites e a Sociologia das Organizações tentando comprovar ou não a hipótese de se os partidos, em suas instâncias organizativas e decisórias principais, apresentam ou não graus de oligarquização. Com o objetivo de demonstrar o que se propõe com a análise, são apresentados empiricamente em quadros os números totais de integrantes de cada executiva estadual pelo nome, função exercida e quantas vezes exerceu cada função. Por fim, a Comissão Executiva é analisada por quatro variáveis que descreverão os níveis de dispersão e/ou concentração das lideranças.

Palavras Chave: Partidos; Oligarquização; Circulação de lideranças; Elites; Comissão Executiva Estadual.

\section{ABSTRACT}

This paper focuses on study the circulation of the party elites on the State Executive Composition of four political parties of Goias State. Therefore, there is a theoretical discussion about the Elite Theory and the Sociology of Organizations trying to prove or not the hypothesis that the party, in their main organizational and main decision-making, present or not degrees of oligarchization. With the aim of demonstrating what the analysis proposes, are empirically presented, in tables, the total numbers of members of each state executive by their names, the function exercised and how many times they performed each function. Lastly, the Executive Commission is analyzed by four variables that will describe the dispersion levels and/or leadership concentration.

Keywords: Parties; Oligarchization; Circulation of Leaders; Elites; State Executive Commission.

\footnotetext{
${ }^{1}$ Esse trabalho faz parte da pesquisa intitulada Política Partidária e Competição Eleitoral em Goiás, coordenada pela Profa. Dra . Denise Paiva Ferreira, da Faculdade de Ciências Sociais da Universidade Federal de Goiás (FCS-UFG), que conta com o apoio institucional da UFG e do Conselho Nacional de Desenvolvimento Científico e Tecnológico (CNPq).

${ }^{2}$ Aluno graduado em Ciências Sociais com habilitação em Políticas Públicas, pela Faculdade Ciências Sociais da Universidade Federal de Goiás (FCS-UFG); bolsista de Iniciação Científica (IC-PIVIC). Promotor Social na Associação Voluntários para o Serviço Internacional (AVSI-BRASIL) e professor de Sociologia no Cursinho Federal de Goiás (EVZ/UFG). E-mail:carlosufg14@gmail.com.
} 


\section{Introdução}

Esta pesquisa apresenta uma discussão sobre a atuação das elites partidárias no Estado de Goiás, analisando especificamente o processo de renovação ou não renovação das lideranças partidárias, por meio da análise empírica sobre a composição de cada Comissão Executiva Estadual de quatro partidos que possuem significativa participação eleitoral, tanto no âmbito federal (Câmara e Senado), quanto na Assembléia Legislativa estadual e Câmaras municipais: Partido do Movimento Democrático Brasileiro (PMDB)/ Movimento Democrático Brasileiro(MDB); Partido da Frente Liberal/Democratas (PFL/DEM); Partido da Social Democracia Brasileira (PSDB) e Partido dos Trabalhadores (PT).

Por elites o estudo se baseia no conceito da teoria das elites, ou elitismo, em que uma minoria é detentora do poder (BOBBIO, MATEUCCI \& PASQUINO, 2007). Essa minoria é compreendida pelos componentes que fizeram parte das executivas estaduais de quatro partidos políticos de Goiás, desde a fundação até o ano de 2017. Por ser a comissão executiva um local específico de tomada de decisões e representar uma característica organizacional que é necessária aos partidos políticos contemporâneos, a pesquisa empírica propõe uma análise sobre elites a partir dos integrantes que fizeram parte de alguns postos chaves das comissões executivas.

Por conta das dificuldades teórico-conceituais que o conceito "oligarquia" tem para a ciência política contemporânea e a necessidade de utilização mais rigorosa do mesmo (COUTO, 2010), escolhemos por uma dentre três formas mais comuns de se utilizar o termo com mais precisão nas ciências sociais contemporâneas (idem), e a que mais se aproxima do propósito da pesquisa, ou seja, uma abordagem micheliana de oligarquia que passa a enfatizar a característica do número em detrimento de riqueza , tratando "oligarquia como um grupo minoritário dotado de grande poder dentro das organizações..."(Ibidem, pg. 5).

Dado as limitações teóricas de Michels (1982) sobre a relação de poder por uma minoria dentro das organizações, o conceito de poder utilizado nesse artigo está bem distante da concepção do autor alemão, dado as limitações que esse conceito enseja para 
a atualidade, não somente dos partidos, mas das organizações contemporâneas. Michels enxerga o poder como uma relação conflituosa já que os interesses dos líderes e seguidores seriam completamente opostos (Medding, 1970). Vivendo numa época de existência dos partidos de massa (Duverger, 1970) a partir da ampliação do sufrágio universal e do surgimento de estruturas políticas de características classistas que mantinham capilaridade com o proletariado, como os sindicatos, Michels não pôde compreender a importância que a burocracia teria para as organizações, como os partidos. A impossibilidade de haver democracia em organizações e sociedades complexas (BRAGA, 2012) levou Michels a conceituar as relações de poder apenas em uma de suas formas, ou seja, o poder coercitivo, negligenciando a relação consensual em que poder também se insere (MEDDING, 1970).

O propósito analítico dessa pesquisa, que se debruçou sobre o fluxo das lideranças partidárias nas comissões executivas, por meio do acesso aos livros de registros e atas se pôde observar eleições periódicas em todos os partidos analisados, se supõe que houve relativa competitividade eletiva para a formação organizativa das comissões. Porém, dado que o retorno do pluripartidarismo em Goiás ocorreu de forma tardia em relação a outros estados da federação (KRAUSE, 2008; PAIVA, 2008 \& BOHN, 2009), pelo qual "a transição política organizou-se primeiramente sob a quase hegemonia do PMDB por um período de quase duas décadas após herdar grande parte da estrutura e bases locais do MDB (PAIVA, 2013, p. 3)”, a análise empírica visa compreender o grau de oxigenação na rotatividade de suas lideranças na organização partidária, dado as características dos partidos contemporâneas em que estão inseridos, de tipo catch-all (KIRCHHEIMER, 1966); profissional-eleitoral (PANEBIANCO, 2005); partido-cartel (MAIR, 2003), além dos fatores históricos elencados e do próprio processo de realinhamento eleitoral e partidário em Goiás, que se seu não por renovação das lideranças, mas por reorganização das elites políticas (PAIVA, 2013).

Desse modo, como a pesquisa privilegia a dimensão organizacional, mesmo que micro e limitada sociologicamente no escopo das comissões executivas, se propõe analisar se existe algum princípio de democratização no processo interno das organizações a partir da possibilidade da circulação de membros aos postos decisórios, ou oligarquização, ou seja, impossibilidade de circulação dos mesmos. A premissa é que 
quanto maior for a possibilidade dos membros alçarem a postos diretivos e decisórios nos partidos, maior a diversificação e possibilidade de renovação das lideranças.

Portanto, o estudo visa elencar os valores irrevogáveis da democracia, principalmente para as organizações. Num país como o Brasil, em que os partidos em geral possuem pouca ou nenhuma capilaridade social, entender ao menos como se configura o espaço decisório a partir das organizações pode trazer elementos substanciais para análises posteriores sobre a sociologia das organizações.

Para o levantamento dos dados empíricos a pesquisa contou com uma análise documental por meio do acesso aos livros de registro e atas, disponibilizados pelos diretórios estaduais de cada partido entre os meses de fevereiro e maio de 2017, nos quais foi possível extrair informações das comissões executivas mais antigas, desde a fundação dos referidos partidos no estado, até o ano de 2017. Os dados a partir do ano de 2006 até 2017 que, por alguma razão, não puderam ser extraídos nos diretórios, foram coletados por meio de consultas online ao Tribunal Regional Eleitoral de Goiás (TRE-GO)33.

$\mathrm{O}$ artigo está estruturado em três partes. Na primeira, é feita uma breve discussão sobre a Teoria das Elites, tendo a contribuição de alguns pensadores e correntes teóricas que ajudaram no desenvolvimento dos estudos das elites, como a “Sociologia das Organizações” de Robert Michels, bem como a contribuição de estudiosos contemporâneos que apresentam elementos outrora não desenvolvidos pela antiga literatura sobre o tema organizacional dos partidos políticos, como Panebianco. Na segunda parte são apresentados os dados coletados dos partidos por meio de quadros onde constam os componentes de cada Comissão Executiva Estadual, a partir de sete funções de uma comissão executiva. Nos primeiros quatro quadros são apresentados informações de todos os integrantes que fizeram parte de cada comissão executiva dos diretórios estaduais, bem como funções e número de vezes que ocuparam cada função, desde a fundação dos partidos até o ano de 2017. Por fim são utilizadas quatro variáveis de autoria própria que irão demonstrar os níveis de circulação dos integrantes de cada

\footnotetext{
3 Infelizmente, para essa pesquisa, não foi possível a colaboração da Comissão Executiva Estadual do Partido Progressista (PP), devido à impossibilidade do Diretório Estadual em disponibilizar os documentos necessários. Foram efetuadas duas visitas ao diretório regional do partido nos meses de fevereiro e março de 2017, além de contatos por e-mail e telefone. No entanto, a postergação em colaborar impediu a inclusão desse partido na pesquisa.
} 
executiva estadual, por partido. Dessas quatro variáveis, três estão classificadas da seguinte maneira: a) Estabilidade Baixa, b) Estabilidade Média, c) Estabilidade Alta e d) Oligárquica ${ }^{4}$. O emprego metodológico da variável "Estabilidade" visa compreender, dentre três níveis, a freqüência em que ocorreu a circulação das lideranças.

Por meio dos resultados obtidos, será demonstrado em quadros algumas especificações da faixa mais "oligarquizada" de cada partido, contendo os nomes, funções exercidas e frequência em cada instância. Em seguida, será elencado qual o partido mais “oligarquizado” mediante a comparação entre as quatro variáveis.

\section{Teoria das elites ou elitismo}

A discussão sobre as elites políticas é algo bem contemporâneo e deve ser creditado aos pais da teoria das elites, ou elitismo, como Mosca, Pareto e Michels. Uma breve análise do século XIX e as implicações que convulsões sociais, econômicas e políticas pelo qual passara a Europa apresentaram elementos que reforçaram a preocupação das elites com a ascenção das massas. Para Miguel (2002, p. 485) "Mosca, Pareto e Michels, não escondiam a sua oposição aos movimentos democráticos e socialistas presentes na virada do século XIX para o século XX". Embora no caso de Michels a elite não tivesse relação diretamente com as classes como em Mosca e Pareto mas sim com a organização, seja de um partido ou um sindicato, o fato é que esse alemão, ex-membro do Partido Social Democrata, exprimia a incompatibilidade entre democracia e as organizações a partir da natureza oligárquica premente nessa última.

A intensificação da luta entre Capital e Trabalho na Europa do século XIX e as tensões políticas e sociais advindas da luta aberta de classes antagônicas entre a burguesia e proletariado fizera eclodir uma onda de questionamentos ao sistema capitalista de produção e a miséria que se emergia das relações desiguais de trocas entre pares tão díspares. Trabalhadores, homens letrados, burgueses com alguma sensibilidade social, reformistas, ideólogos e espectros distintos de ideologias - cada qual com suas armas e estratégias - ditavam a escalada das massas trabalhadoras ora na

\footnotetext{
${ }^{4}$ O emprego da variável "estabilidade" e "oligárquica" foi desenvolvida como aporte metodológico afim de comprovar empiricamente se há relação dos dados coletados com a pergunta da pesquisa.
} 
tomada e destruição do aparelho estatal e fundação de uma nova sociedade, como o anarquismo e o socialismo científico de Marx; por estratégias reformistas de todas as matizes, como o movimento cartista, que impunha o martelo afim de destruir a materialidade de sua exploração (as máquinas) ; ou pelos socialistas utópicos como Owen, Saint Simon e Fourrier, adeptos das cooperativas harmônicas e na demasiada crença na solidariedade humana, como em Owen.

No entanto, uma "crença” no colapso do capitalismo pela ascensão da classe trabalhadora ao aparelho repressivo que é o Estado e na re-fundação de uma nova sociedade sem exploração e baseada na comunidade igualitária entre todos, como no comunismo de Marx, não ocorreu. Liberais como John Stuart Mill tiveram de reconhecer a necessidade de governos representativos que objetivassem a participação dos trabalhadores pelo sufrágio universal, o que fortaleceu a legitimidade das instituições burguesas como parlamento ao mesmo tempo em que proporcionou o arrefecimento das táticas frontais e revolucionárias ainda no espectro de um comunismo que rondava a Europa, como dizia Marx, com o iminente perigo de um levante massivo do proletariado, que colocasse abaixo o capitalismo e o próprio estado burguês.

Com a criação dos primeiros partidos políticos de massa e dos sindicatos na Europa e o recrutamento cada vez maior de trabalhadores nesses órgãos políticos suscitou preocupação nas elites quanto ao espaço que esses atores poderiam ter nos processos decisórios que pudesse alterar o status quo. Não obstante, os trabalhadores organizados passaram a ser vistos de forma pormenorizada e malquistos pelas elites, servindo-se de escopos à diversas matizes teóricas e interpretativas dos autores da teoria das elites, ou elitismo (BOBBIO, MATEUCCI \& PASQUINO, 2007).

A discussão sobre quem e quantos devem governar é um dos questionamentos mais clássicos sobre a função da política, a partir da análise sobre as formas de governo e dos tipos constituições de cada estado. Foge do propósito desse artigo em esmiuçar sobre esses elementos, nos competindo apenas em reforçar que a questão numérica de quem manda e quantos mandam sempre esteve presente na historiografia política, o que ressoou também na discussão conceitual dos teóricos do elitismo. A expansão do sufrágio universal no final do século XIX levantou uma série de questionamentos e preocupações com os setores dominantes da sociedade e isso ressoou no surgimento de 
teorias que enfatizaram a questão numérica afim de justificar uma elite governante, que por questões organizacionais e civilizacionais, deveria ser sempre uma minoria.

Gaetano Mosca, influenciado pelo rigor científico das ciências naturais e do legado de Darwin às estruturas de organização e evolução das espécies animais que tendiam a uma lei de sobrevivência do mais apto em detrimento de outros que pereceriam frente ao mais forte, entendia que a observação dos fenômenos sociais deveria se embasar pelo rigor por uma cientificidade que se pautaria na evolução das sociedades humanas e da civilização sempre como condução pelos mais aptos. Adotando o método histórico e comparativo como o mais adequado à observação dos fenômenos Mosca propôs considerações que seriam elencadas "a partir da observação dos variados grupos e organismos políticos, em diferentes períodos históricos e em diversos tipos de civilização" (PERISSINOTTO, 2009, p. 24; GIMENES, 2014, p. 126). Para Mosca, em toda sociedade sempre existiu duas classes: a dos governantes, ou a classe política e a classe dirigente e os governados, que na contemporaneidade passaram a ser chamados de massa. Mas o que devemos chamar a atenção da conceituação de Mosca sobre a teoria elitista diz respeito o ao predomínio de uma minoria, pela qual, pertencendo a um nicho pequeno de pessoas com interesses homogêneos facilitaria a organização e a governabilidade, em detrimento de grupos mais vastos e com interesses heterogêneos, como as massas, que na busca pelos interesses individuais culminaria na desorganização e na desgovernabilidade (GIMENES, 2014). Com base nesse caráter numérico para uma teoria das organizações de Mosca podemos dizer que "a teoria da classe política é habitualmente também chamada teoria da minoria organizada" (BOBBIO, MATTEUCCI \& PASQUINO, 2007, pg. 386).

Já Vilfredo Pareto, reconhecendo a heterogeneidade humana pela qual os indivíduos possuem diferenças intelectual, moral e física, o que caracteriza a distinção da sociedade em estratos superior e inferior, estabeleceu que os indivíduos pertencentes a classe superior seriam aqueles possuidores da excelência no desempenho de suas atividades. Ao contrário de Mosca, a elite não estaria relacionada apenas com quem governa e participa direta ou indiretamente do governo, mas também por aqueles que mesmo não participando das decisões políticas poderiam vir a influenciar por meios de recursos das quais dispunham o processo decisório e de poder. 
Como primeiros teóricos que analisaram, mesmo que incipiente, aspectos organizacionais dos partidos políticos europeus, ainda em meados do século XX, tanto Ostrogorski (1970) e principalmente Michels (1982), foram pioneiros na análise da estrutura interna dos partidos. O teor oligárquico das organizações está presente em ambos, onde a terminologia oligarquia fora utilizada para demonstrar "um grupo minoritário dotado de grande poder dentro de organizações (COUTO, 2010, p. 5).

Cabe salientar que Michels foi um dos responsáveis pelo deslocamento terminológico do conceito de oligarquia que, desde a formulação grega clássica que o tratava como forma de governo, ou governo dos ricos, passou-se á esfera minoritária de um grupo que limitaria os ensejos da maioria (Idem).

A sociologia das organizações de Michels, ao analisar a estrutura dos grandes partidos de massa da Europa no começo do século XX e, principalmente, o partido social democrata alemão (SPD), identificou um princípio oligárquico que não adviria diretamente dos grupos sociais - como as duas classes existentes em toda sociedade entre governantes e governados em Mosca, ou a elite governante e não governante e as massas em Pareto - mas da própria organização. Uma vez que não haveria possibilidade de democracia sem organização e sendo a organização tendenciosamente oligárquica pela qual a especialização e a profissionalização das funções no seio dos partidos tenderia a formar uma casta de burocratas, abriria um fosso entre os dirigentes partidários e as massas já que os interesses minoritários da organização se sobressairia aos interesses da coletividade, fadando o socialismo e a própria democracia ao cadafalso das oligarquias ou elites.

A própria definição da Teoria das Elites, ou “elitismo", segundo o Dicionário de Política (BOBBIO, MATTEUCCI \& PASQUINO, 2007. p. 385) está explicito o caráter quantitativo do conceito, onde:

Por teoria das elites ou elitista - de onde também o nome de elitismo- se entende a teoria segundo a qual em toda a sociedade, existe, sempre e apenas, uma minoria que, por várias formas, é detentora do poder, em contraposição a uma minoria que dele está privada.

Desse modo, a questão numérica de quem detém o poder tende a ser sempre de uma minoria. Isso é importante porque o estudo sobre as elites se inicia já em um 
contexto histórico contemporâneo, ou seja, do final do século XIX para o início do século $\mathrm{XX}$, em pleno período de desenvolvimento da democracia representativa liberal e suas instituições, como o Parlamento, e os próprios partidos políticos.

Embora as contribuições de todos os autores clássicos que trataram sobre as elites políticas carecessem de comprovação empírica, foram importantes para estudos posteriores sobre a teoria das organizações. No entanto, dado a limitação teórica conceitual dos primeiros estudos sobre as organizações de Michels (1982) e da diferença dos partidos contemporâneos para os antigos partidos, principalmente os partidos de massa (DUVERGER, 1987) da primeira metade do século XX, se faz necessário o aporte de outros autores contemporâneos afim de um aprofundamento teórico-conceitual sobre os partidos e organizações. O escopo teórico sobre oligarquias parte das contribuições de Robert Michels por duas razões simples: 1) a abordagem sobre as elites mediante as organizações e 2) a hipótese do descompasso entre organização e democracia. Michels é utilizado como aporte inicial apenas. Muitas de suas análises não se aplicam aos dias atuais, onde se faz necessário a contribuição de outros autores contemporâneos que analisaram aspectos externos sobre a organização, como a competição eleitoral e a influência dos meios de comunicação que transformaram a relação membros/lideranças.

\section{A Sociologia das Organizações: de Michels a Panebianco}

Iniciamos essa secção fazendo algumas observações importantes quanto ao emprego da Teoria das Elites de Michels à atualidade. Do ponto de vista histórico e conceitual, são necessárias algumas ressalvas e assertivas. Das ressalvas é preciso distinguir a incompatibilidade temporal, tipo de partido e tipo de organização partidária que o autor está tratando, em sua obra máxima "A Sociologia dos Partidos Políticos" (MICHELS, 1982). A incompatibilidade temporal e do tipo de partido se dá pelo período em que Michels escreveu a obra, entre as primeiras duas décadas do século XX, época de ouro dos partidos de massa na Europa e que, no Brasil, segundo Melo (2007), tivemos apenas uma ligeira experiência quando da criação do PT, ainda nos anos 8o. Já a ressalva na abordagem das organizações diz respeito que esse autor trata por organização a 
especialização de funções que levam a profissionalização de poucos. Desse modo, se formaria uma casta de especialistas que não podendo ser descartados pelas massas, tornaria a organização não mais como um meio para alcance dos interesses dos grupos, mas um fim em si mesmo

Para compreendermos esse "fim em si mesmo" de Michels precisamos voltar no tempo a partir dos aspectos do partidos de massa do começo do século XX, para daí fazermos uma analogia com a literatura contemporânea sobre organização partidária. A época de Michels coincide com os partidos de massa onde os partidos, principalmente os socialistas, o vínculo classista entre eleitores e partidos era muito forte (DUVERGER, 1987). Desse modo, “a distinção e a caracterização elaboradas por Duverger fizeram com que o autor definisse o partido de massa como modelo de partido mais adaptado às condições impostas pela democracia direta" (AMARAL, 2013).

No período pós II Guerra Mundial outros fatores contribuíram para mudar a estrutura organizacional dos partidos e sua relação com os eleitores. A partir das análises de Kirchheimer (1966) a configuração classista que existia nos antigos partidos de massa foi moldada. A característica de classe dos membros já não era mais relevante e a obtenção do maior número de votos para a vitória dos partidos nas eleições passou a ser o principal motivo, ficando caracterizados como partidos catch all parties (idem). A influência das disputas eleitorais moldou decisivamente a estrutura partidária preconizado por Michels, onde a organização não era mais um fim em si mesmo, mas uma necessidade na disputa eleitoral e pela sobrevivência frente aos meios de comunicação.

Já Panebianco (2005) foi responsável por criar uma teoria sobre partidos políticos de maneira profícua das estruturas organizacionais e sua adaptabilidade em distintos ambientes. Para Panebianco as estruturas originárias dos partidos são moldadas para atender as necessidades externas, como as eleições. Ele caracteriza os partidos como profissional-eleitoral, onde a profissionalização transforma a burocracia já que o especialista, o técnico, passa a ser o garantidor da vitória eleitoral, e não mais a militância ou membros.

Portanto, diferente da época de Michels em que o avanço tecnológico e os meios de comunicação ainda eram incipientes aos padrões modernos, o contexto onde ocorre 
o multipartidarismo e a volta da democracia no Brasil já traz em seu bojo uma dinâmica diferente. A TV exerce o lugar do palanque, ditando o caráter personalista das lideranças partidárias e diminuindo a importância programática e ideológica dos partidos (GUNTHER; DIAMOND, 2015).

Além disso, os partidos políticos nos últimos quarenta anos sofreram uma tendência de diminuição de suas funções representativas, passando da esfera da sociedade civil para a esfera do Estado, de uma função mais representativa para uma função mais governativa (MAIR, 2003). O acesso aos recursos estatais, como verbas e tempo de TV na propaganda eleitoral, tornou a importância da identidade ideológica e programática, secundária (Idem.)

Destarte, o próprio período em que as disputas partidárias ressurgem no Brasil, a partir do retorno ao multipartidarismo em 1979, coincide com o período de proliferação dos Partidos Eleitoralistas, ou do tipo Catch All (MAINWARING, 2001) 5 .

Em Goiás o realinhamento partidário após a transição do período autoritárioburocrático para a democracia se deu primeiramente sob a hegemonia de quase duas décadas do PMDB, que herdou a estrutura do antigo MDB. Desse modo o pluripartidarismo ocorreu de forma mais tardia em Goiás em detrimento de outros estados da federação (KRAUSE, 2008; PAIVA 2008; PAIVA \& BOHN, 2009). Isso demonstra que o realinhamento do sistema partidário em Goiás não se deu por um processo de renovação, mas sim de uma reorganização das elites políticas (PAIVA, 2013).

Outro fator que pode corroborar na hipótese dos partidos como um fim em si mesmo micheliano e propensos a perpetuarem elites, tornando-se "oligárquicos", diz respeito ao enfraquecimento dos vínculos entre os partidos políticos no Brasil e a sociedade estar relacionado com inúmeras experiências de mudanças dos regimes políticos que coincidiram com as mudanças também dos sistemas partidários (MELO, 2007). O próprio sistema atual partidário emergiu ainda no final da década de 1970 do século XX, depois de apenas 15 anos de bipartidarismo e, antes desse, de 19 anos de multipartidarismo, só para citar as três últimas experiências de sistemas partidários no

\footnotetext{
5 Conceito empregado por Otto Kirchheimer para caracterizar o partido que em detrimento da necessidade de conquistar o maior número de votos possíveis disputa um eleitorado que possui todas as matizes político-ideológicas, enfraquecendo, desse modo, os objetivos programáticos iniciais do partido e a coesão ideológica partidária.
} 
Brasil. Desse modo, mudando-se os regimes, mudam-se os partidos, o que pode acarretar ou não na natureza oligárquica das organizações partidárias.

Para finalizar, depois de elencar todas essas características que podem ajudar a confirmar ou não a hipótese de que nos partidos de Goiás (PMDB, PFL/DEM, PT e PSDB) há mais propensão à circulação das lideranças partidárias, tornando-os menos oligárquicos, ou o contrário, após apresentarmos a metodologia, nos esmiuçaremos na análise empírica da composição executiva estadual de cada partido.

\section{Metodologia}

A coleta de dados em livros de atas e registros de três dos quatro partidos ${ }^{6}$ foi efetuada utilizando-se um aparelho celular com dispositivo de foto. Por se tratar de documentos antigos e disponíveis somente para consulta no próprio diretório, foram fotografadas as páginas que continham informações pertinentes aos membros que fizeram parte das comissões. Na impossibilidade de identificar em algum período a lista completa de toda a composição em atas e livros de registro, se fez necessário extrair as páginas que continham nomes de alguns integrantes e seus respectivos cargos.

O emprego metodológico da variável "Estabilidade" visa compreender, dentre três níveis, a freqüência em que ocorreu a circulação das lideranças. Por Estabilidade Baixa se compreende os integrantes que exerceram apenas uma função, uma única vez, não resultando em estabilidade duradoura. Essa é a faixa de maior oxigenação da Executiva porque quanto maior o número de indivíduos que exerceram apenas uma função, maior a rotatividade interna. Por Estabilidade Média compreende-se a faixa dos integrantes que exerceram apenas duas funções, em uma ou duas instâncias. Já a Estabilidade Alta diz respeito aos integrantes com apenas três funções exercidas, em uma, duas ou três instâncias. Essa faixa recebe o adjetivo de alta porque possui estabilidade maior devido ao número de cargos exercidos ser superior à Estabilidade Baixa e Estabilidade Média e muito próximo da faixa de maior concentração de funções,

\footnotetext{
${ }^{6}$ O Partido dos Trabalhadores encaminhou ao e-mail desse pesquisador uma lista contendo a Comissão Executiva do Partido, desde 1980 até 2017. Desse modo, não foi preciso a consulta aos documentos no diretório estadual.
} 
a qual designaremos como Oligárquica. Por variável "Oligárquica", compreende-se os integrantes que exerceram mais de três funções, em uma ou mais instâncias. Essa é a faixa de menor circulação das lideranças dado a concentração maior de funções por um menor número de pessoas. Isso pode indicar se a natureza oligárquica dessa faixa é mais vertical, ou seja, maior que três funções exercidas em uma única instância, ou horizontal, maior que três funções exercidas em instâncias diferentes.

A análise sobre a composição executiva se deu a partir da escolha de alguns cargos que o entendemos como chave para a composição de lideranças. São elas: 1) Presidente; 2) 1o Vice-Presidente; 3) 2o Vice-Presidente; 4) 3o Vice-Presidente; 5) Secretário Geral; 6) 1o Secretário e 7) Tesoureiro.

\section{Comissão Executiva Estadual do PSDB em Goiás - 1990-2017}

O Partido da Social Democracia Brasileira (PSDB) foi fundado em Junho de 1988. É um partido que se localiza no espectro ideológico de centro (WIKIPÉDIA). Em Goiás, a primeira Comissão Executiva Estadual foi formada em 1990. Dos dados levantados durante a consulta aos livros de atas e documentos do partido, além de consulta ao TRE, foi possível identificar 47 integrantes que atuaram nas instâncias da composição executiva estadual, entre 1990 e 2017. Além disso, é demonstrado o número de vezes em que cada integrante ocupou a mesma função e/ou funções diferentes, conforme quadro abaixo:

\section{Quadro 1.1. Composição da Comissão Executiva do Diretório Estadual do PSDB} 1990-2017

\begin{tabular}{|l|c|c|c|c|c|c|c|}
\hline Titular do cargo & Presid. & $\begin{array}{c}\mathbf{1}^{\mathbf{0}} \text { Vice } \\
\text { Presid. }\end{array}$ & $\begin{array}{c}\mathbf{2}^{\mathbf{0}} \text { Vice } \\
\text { Presid. }\end{array}$ & $\begin{array}{c}3^{\mathbf{0}} \text { Vice } \\
\text { Presid. }\end{array}$ & $\begin{array}{c}\text { Sec. } \\
\text { Geral }\end{array}$ & Sec. & Tes. \\
\hline Mauro C. Neto & $\mathbf{1}$ & & & & & & \\
\hline Nelson de Salles & & 1 & & & & & \\
\hline Gerson Martins & & 1 & 1 & & & & \\
\hline Genaro S. Filho & & & & & 1 & & \\
\hline Lennine Bueno & & & & & & 1 & \\
\hline Paulo S. Jesus & 2 & & & & 1 & 3 & 3 \\
\hline
\end{tabular}




\begin{tabular}{|c|c|c|c|c|c|c|c|}
\hline Kleber Adorno & 1 & & & & & & \\
\hline Elias Rassi & & & 1 & & & & \\
\hline Jovair Arantes & & & & & 2 & & \\
\hline Itamar de Souza & & & & & & 1 & \\
\hline Antonio Faleiros & 3 & 1 & & & & & 1 \\
\hline Iron Alvez & & 1 & & & & & \\
\hline Fernando Safatle & & & 1 & & & & \\
\hline Juvenal Raimundo & & & & & 1 & & \\
\hline Jonathas Silva & 2 & & & & & 1 & \\
\hline Carlos Eurico & 1 & & & & & & 1 \\
\hline Henrique Santillo & 1 & & & & & & \\
\hline Marconi Perillo & & 1 & & & & & \\
\hline Olier Alves & & & 2 & & & & \\
\hline Regina Lopes & & & & & & 2 & \\
\hline Carlos Alberto S. & & 1 & 1 & & & & \\
\hline Honor Cruvinel & & & & & 1 & & \\
\hline Daniel Goulart & & 1 & & & & & 1 \\
\hline Joaquim Alves & & & 1 & & & & \\
\hline José C. Debrey & & & & & 1 & & \\
\hline Edmundo Dias & & 1 & & & & & 6 \\
\hline Wladmir Garcêz & & 1 & & & & & \\
\hline Julio S. de Melo & & & 1 & & & & \\
\hline Lucia Vânia & & 1 & & & & & \\
\hline Sérgio Cardoso & & & 1 & & 3 & & \\
\hline Samuel Almeida & & & & & 1 & & \\
\hline Leonardo Vilela & 1 & & & & & & \\
\hline Daniel Goulart & & 1 & & & & & \\
\hline Fabio de Souza & & & & & & 1 & \\
\hline Jurandir Augusto & & 2 & & & & & \\
\hline Sônia Chaves & & & 2 & & & & \\
\hline Carlos Lereia & & & & 1 & & & \\
\hline Eliane Pinheiro & & & & & & 1 & \\
\hline Cristina Lopes & & & & 1 & & & \\
\hline Thiago Albernaz & & & & & & 1 & 1 \\
\hline Afrêni G. Leite & 1 & & & & & & \\
\hline Gustavo Sebba & & & 2 & & & & \\
\hline Lêda Borges & & & & 2 & & & \\
\hline João Meireles & & & & & 2 & & \\
\hline Daniela Vaz & & & & & & 2 & \\
\hline Giusepe Vecci & 1 & & & & & & \\
\hline José A.Vitti & & 1 & & & & & \\
\hline
\end{tabular}

Fonte: Diretório Estadual do PSDB e TRE. ${ }^{7}$

7 A Referência para todas as tabelas do PMDB, PSDB, PFL/DEM está disponível em: http://www.tse.jus.br/partidos/partidos-politicos/modulo-consulta-sgip3. Acesso em 15 de Abril de 2017. 
O quadro 1.1 apresenta a distribuição dos integrantes da Comissão Executiva Estadual do PSDB, de 1990 a 2017, da seguinte forma: Presidente (10); 1o Vice-Presidente (13); 2º Vice-Presidente (10); 3ํㅡㄹce-Presidente (3); Secretário Geral (9); 1o Secretário (9) e Tesoureiro (6). Alocação de 47 integrantes, dentre as quatro variáveis: Estabilidade Baixa (28); Estabilidade Média (14); Estabilidade Alta (1); Oligarquização (4).

\section{Comissão Executiva Estadual do PFL/DEM ${ }^{8}$ em Goiás -1985-2017}

O Partido da Frente Liberal (PFL) foi um partido de centro-direita (WIKIPÉDIA) fundado em 1985 por uma dissidência do extinto Partido Democrático Social (PDS), em pleno processo de redemocratização. Assentado numa ideologia conservadora e liberal, o partido mudou de nome e a partir de 2007 passou a se chamar DEMOCRATAS. O Democratas é um partido do espectro centro-direita assentado numa filosofia política conservadora-liberal (Idem).

Em Goiás, a primeira Comissão Executiva do PFL foi formada também em 1985. Por meio de consultas aos livros de ata e documentos extraídos do Diretório Estadual do DEM em Goiânia, além de pesquisas ao Tribunal Regional Eleitoral de Goiás (TRE-GO), foram identificados 32 integrantes que fizeram parte das composições da executiva estadual tanto no período de vigência do PFL (1985/2007), quanto no período vigente do DEM, de 2007 até a atual composição, conforme quadro abaixo.

\footnotetext{
${ }^{8}$ A pesquisa aos primeiros livros de atas do Partido da Frente Liberal (PFL) em Goiás revelou que houve uma longa interrupção do processo de escolha da Composição da Comissão Executiva do partido entre os anos de 1998 a 2006. Nesse período não foi encontrado registros de qualquer composição formada, com nomes e funções, mas sim apenas atas com assuntos mais gerais do partido contendo menção ao presidente Ronaldo Caiado às reuniões. Essas identificações que só indicaram quem era o presidente do partido foram extraídas de uma ata de 1998, 2000, 2003 e 2006. Já a ata de 2006 foi a última do Partido da Frente Liberal e continha o nome do presidente, secretário-geral e tesoureiro. A falta de informações das composições da executiva estadual do PFL entre os anos de 1998 a 2006 confirma apenas que Ronaldo Caiado exerceu o cargo de presidente em todos esses anos, não possibilitando o conhecimento dos outros componentes que fizeram parte da executiva. Portanto, não podemos negligenciar o fato de que o numero de 32 integrantes identificados na análise documental de todas as comissões da executiva estadual do PFL (1985-2006) se baseia naquilo que foi encontrado nos registros e não o numero de integrantes que realmente compuseram as instâncias executivas do partido, entre 1998 e 2006. Nas visitas ao diretório do DEM curiosamente as atas e documentos com informações desse partido não estavam no Diretório. Foram extraídas todas as informações pertinentes ao período do PFL. Já as informações do próprio DEM só foi possível através do banco de dados do TRE-GO.
} 
Quadro 1.2. Composições da Comissão Executiva do Diretório Estadual do PFL/DEM 1985- 2017

\begin{tabular}{|c|c|c|c|c|c|c|c|}
\hline Titular do cargo & Presid. & $\begin{array}{l}1^{\circ} \text { Vice } \\
\text { Presid. }\end{array}$ & $\begin{array}{l}2^{\circ} \text { Vice } \\
\text { Presid. }\end{array}$ & $\begin{array}{l}3^{\circ} \text { Vice } \\
\text { Presid. }\end{array}$ & $\begin{array}{l}\text { Sec. } \\
\text { Geral }\end{array}$ & $1^{\mathrm{o}}$ Sec. & Tes. \\
\hline Vilmar Rocha & 3 & & & & & & \\
\hline Felisberto Jacomo & & 1 & & & & 2 & \\
\hline Oton Nascimento & & & & & 1 & & 1 \\
\hline João Veloso & & & & & & 1 & \\
\hline Alcides Inácio & & & & & & & 3 \\
\hline Jarmund Nasser & & 2 & & & & & \\
\hline Juracy Teixeira & & & 2 & & & & \\
\hline Pedro Canedo & & & & & 2 & & \\
\hline Délio Braz & 1 & & & & & & \\
\hline Délio Senna & & 1 & & & & & \\
\hline Cleuzita de Assis & & & 1 & & & & \\
\hline Edmundo Neto & & & & & 1 & & \\
\hline Ézio Gomes & & & & & & 1 & \\
\hline Jalles Siqueira & & & & & & & 1 \\
\hline Ronaldo Caiado & 6 & & & & & & \\
\hline Odair Resende & & 1 & & & & & \\
\hline Valcenor Braz & & & 1 & & & & \\
\hline Hélio de Souza & & & & 1 & 1 & & \\
\hline Diogenes M. & & & & & & 1 & \\
\hline Demóstenes T. & & 1 & 1 & & & 1 & \\
\hline José E. Fleury & & & 1 & & & & \\
\hline Luis C. Rates & & & & & 4 & & \\
\hline Joel Braga Filho & & & & & & & 3 \\
\hline José Eliton & & 1 & & & & & \\
\hline Dione Araujo & & 1 & & 1 & & & \\
\hline David Souza & & & & & & 1 & \\
\hline Wilder Moraes & & 1 & & & & & \\
\hline Rafael Raffif & & & 1 & & & & \\
\hline $\begin{array}{l}\text { Anderson } \\
\text { Holanda }\end{array}$ & & & 1 & & & & \\
\hline Silvio Antonio & & & & 1 & & & \\
\hline Roseli Oliveira & & & & & & 1 & \\
\hline Marcos Roberto & & & & & & & 1 \\
\hline
\end{tabular}

Fonte: Diretório Estadual do DEM e TRE. 
O quadro 1.2 apresenta os 32 integrantes que fizeram parte da Composição da Executiva Estadual do PFL/DEM (1985-2017), nas seguintes instâncias: Presidente (3); $\mathbf{1}^{\mathbf{o}}$ Vice-Presidente (8); $2^{\underline{0}}$ Vice-Presidente (7); $3^{\underline{0}}$ Vice-Presidente (3); Secretário Geral (6); 1o Secretário (6) e Tesoureiro (6). Alocação dos 32 integrantes, dentre as quatro variáveis: Estabilidade Baixa (19); Estabilidade Média (6); Estabilidade Alta (5); Oligarquização (2).

\section{Comissão Executiva Estadual do PMDB/MDB9 em Goiás - 1985-2017}

O Partido do Movimento Democrático Brasileiro (PMDB) é um partido político que possui um espectro ideológico de Centro (WIKIPÉDIA). Fundado em 1980, após o retorno ao multipartidarismo, foi o sucessor do Movimento Democrático Brasileiro (MDB), criado em 1966 para ser oposição ao regime autoritário, instaurado em 1964. Em Goiás, a primeira Comissão da Executiva Estadual do partido foi formada em 1985, conforme a pesquisa aos livros de atas no diretório estadual do Partido, em Goiânia. Além disso, o partido disponibilizou também os primeiros livros de atas do MDB, datados a partir do ano de 1966, mas que não fazem parte dos objetivos dessa pesquisa, conforme quadro abaixo.

\section{Quadro 1.3. Composições da Comissão Executiva do Diretório Estadual do PMDB/MDB - 19852017}

\begin{tabular}{|l|c|c|c|c|c|c|c|}
\hline Titular do cargo & Presid. & $\begin{array}{c}\mathbf{1}^{\mathbf{0}} \text { Vice } \\
\text { Presid. }\end{array}$ & $\begin{array}{c}\mathbf{2}^{\mathbf{0}} \text { Vice } \\
\text { Presid. }\end{array}$ & $\begin{array}{c}3^{\mathbf{0}} \text { Vice } \\
\text { Presid. }\end{array}$ & $\begin{array}{c}\text { Sec. } \\
\text { Geral }\end{array}$ & $\mathbf{1}^{\circ}$ Sec. & Tes. \\
\hline Tobias Neves & 1 & & & & & & \\
\hline Juarez Magalhães & 1 & & & & 2 & & \\
\hline $\begin{array}{l}\text { Francisco } \\
\text { Brandão }\end{array}$ & 1 & & & & & & \\
\hline Joaquim Roriz & & 1 & & & & & \\
\hline João Natal & & & 1 & & & & \\
\hline Francisco Castro & & & & & 3 & 1 & \\
\hline Jacques de Souza & & & & & & & 1 \\
\hline Pedro Celestino & 1 & & & & & & \\
\hline
\end{tabular}

\footnotetext{
9 Em 2018 houve uma mudança na nomenclatura do partido, passando de PMDB a ser denominado novamente como MDB (Movimento Democrático Brasileiro).
} 


\begin{tabular}{|c|c|c|c|c|c|c|c|}
\hline Onofre Guinan & & 1 & & & & & \\
\hline Osmar Xerxes & & & & & 1 & & \\
\hline Carlos Brandão & & & & & & 1 & \\
\hline Hélio Santana & & & & & & & 1 \\
\hline Luiz A. Soyer & 1 & & & 1 & & & \\
\hline $\begin{array}{l}\text { Jossivani de } \\
\text { Oliveira }\end{array}$ & & & & & & 1 & \\
\hline Iris Rezende & 4 & & & & & & \\
\hline Lazaro Ferreira & & 1 & & & & & \\
\hline Lydia Guinan & & & 1 & & & & \\
\hline Harley Magon & & & & 1 & & & \\
\hline Mário Ghannan & & & & & & 1 & \\
\hline Geraldo Bibiano & & & & & & & 2 \\
\hline Mauro Miranda & & 1 & & & & & \\
\hline Helenês Candido & 1 & & 1 & & & & \\
\hline Mara Naves & & & & & & 1 & \\
\hline José Avelino & & & & & & 1 & \\
\hline Nailton Silva $^{10}$ & 2 & 1 & 1 & & & & \\
\hline Maguito Vilela & 1 & & & & & & \\
\hline Adib Elias Junior & 2 & 1 & & & & & 1 \\
\hline Wagner Silva & & 1 & 1 & & & & \\
\hline Ney Moura Teles & & & & 1 & & & \\
\hline Pedro Chaves & & & 3 & & 1 & & \\
\hline Thiago Peixoto & & & & & & 1 & \\
\hline Eli de Faria & & & & & & & 1 \\
\hline Leandro Vilela & & 2 & & 1 & & & \\
\hline Kid Neto & & & & & 2 & & \\
\hline Flavio Rios & & & & & & 1 & \\
\hline Sebastião Pereira & & & & & & & 1 \\
\hline Samuel Belchior & 2 & & & & & & \\
\hline Bruno Peixoto & & & & 2 & & & \\
\hline Paulo C. Martins & & & & & 3 & & \\
\hline Daniel Vilela & 1 & & & & & 1 & \\
\hline Wolney Siqueira & & & & & & & 1 \\
\hline Luiz C. Carmo & & & & & & & 1 \\
\hline José Nelto & & 1 & & & & & \\
\hline
\end{tabular}

${ }^{10}$ De acordo com as atas do Diretório Regional, no dia o9 de Agosto de 2004 o então Senador e presidente do PMDB, Iris Resende Machado, solicitou a licença do cargo e designou o então $\mathbf{1}^{\circ}$ Vice-Presidente, Nailton Silva, que ocupasse a função até 31 de outubro daquele ano, o que foi prontamente aprovado. No dia $1^{\circ}$ de novembro de 2004 foi solicitado e aprovado a prorrogação da licença de Iris Resende até o dia 31 de Dezembro de 2004, permanecendo o 1 $^{-}$Vice-Presidente na condição de presidente, interinamente. Já no dia 06 de Janeiro de 2005 Iris Resende solicitou mais uma prorrogação da licença do cargo de presidente, por tempo indeterminado, bem como a continuidade do presidente interino, também por tempo indeterminado. Nailton Silva exerceu o cargo de presidente do PMDB até meados de 2006, quando foi eleita uma nova Comissão Executiva. Fonte: Diretório Estadual do PMDB. 


\begin{tabular}{|l|l|l|l|l|l|l|l|} 
Ernesto G. & & & & 1 & & & \\
\hline Gilmar Alvez & & & & & & 1 & \\
\hline
\end{tabular}

Fonte: Diretório Estadual do PMDB e TRE.

O quadro 1.3 apresenta a distribuição dos integrantes nas composições da Executiva Estadual do PMDB (1985-2017) ${ }^{11}$, extraídos das atas, da seguinte forma:

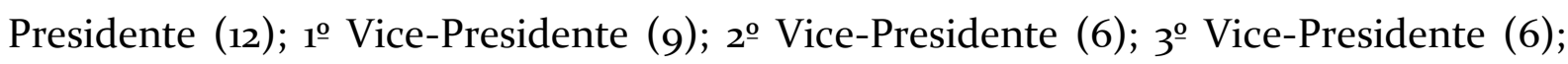
Secretário Geral (6); 1o Secretário (10) e Tesoureiro (8). Alocação dos 45 integrantes, dentre as quatro variáveis: Estabilidade Baixa (29); Estabilidade Média (8); Estabilidade Alta (3); Oligarquização (5).

\section{Comissão Executiva Estadual do PT em Goiás - 1980-2017}

O partido dos trabalhadores (PT) foi fundado em 1980. É um partido que se encontra no espectro político de esquerda (WIKIPÉDIA). Em Goiás, a primeira Comissão Executiva foi formada também em 1980. O Diretório estadual do Partido dos Trabalhadores em Goiânia disponibilizou uma lista ${ }^{12}$ das composições da Executiva Estadual do partido, que foi encaminhada por e-mail.

\section{Quadro 4.1. Composições da Comissão Executiva do Diretório Estadual do PT -}

$$
1980-2017^{13}
$$

\begin{tabular}{|c|c|c|c|c|c|c|c|}
\hline Titular do cargo & Presid. & $\begin{array}{l}\text { 1 Vice }^{\text {Presid. }} \\
\text { Pris. }\end{array}$ & $\begin{array}{l}2^{\circ} \text { Vice } \\
\text { Presid. }\end{array}$ & $\begin{array}{l}3^{0} \text { Vice } \\
\text { Presid. }\end{array}$ & $\begin{array}{c}\text { Sec. } \\
\text { Geral }\end{array}$ & $1^{\circ}$ Sec. & Tes. \\
\hline Línio de Paiva & 1 & & & & & & \\
\hline Cesar Bastos & & 1 & & & & & \\
\hline Athos Magno & 3 & & & & 1 & & \\
\hline
\end{tabular}

\footnotetext{
${ }^{11}$ Houve uma dificuldade em se precisar o número efetivo de membros de cada instância da executiva estadual do PMDB porque nas primeiras atas não foi identificado informações mais gerais, como tesoureiro, $\mathbf{1}^{\mathbf{0}}$ Secretário, $1^{\mathbf{0}}, 2^{\mathbf{0}}$ e $3^{\mathbf{0}}$ Vice-Presidente. Desse modo, os dados inferidos das primeiras executivas diz respeito aos cargos que foi possível identificar nas atas, sem negligenciar o fato de que outros integrantes devem ter feito parte da comissão executiva.

${ }_{12}$ Agradecimentos a Sra. Neyde Aparecida da Silva, que trabalha na secretaria do partido, por ter disponibilizado os dados.

${ }^{13}$ Cabe ressaltar que de 1980 até 2001 a Comissão Executiva do PT foi formada sem eleições diretas. Somente em Novembro de 2001 é que houve a primeira executiva eleita por eleições diretas. Fonte: Diretório regional do Partido dos Trabalhadores em Goiás.
} 


\begin{tabular}{|c|c|c|c|c|c|c|c|}
\hline Augusto Cesar & & & & & 1 & 1 & \\
\hline Alberto Gomes & & & & & & & 1 \\
\hline Antônio Alonso & & 1 & & & & & \\
\hline Exupério Alves & & & 1 & & & & \\
\hline Pedro Wilson & & 1 & & & 1 & & \\
\hline Maria José & & & & & & 1 & \\
\hline Athos Pereira & 1 & 2 & & & & 1 & 1 \\
\hline Paulo Augusto F. & & 1 & & & & & \\
\hline Robinho Martins & & & 2 & & & & \\
\hline Rubens Otoni & 3 & & & & 1 & & \\
\hline Antônio Salles & & 1 & & & & 1 & 1 \\
\hline Fausto Jaime & 1 & 1 & & & & & \\
\hline Valdi Camarcio & 3 & 3 & & & & & \\
\hline Delubio Soares & & & 1 & & & & \\
\hline Hamilton Pereira & & & & & & 1 & \\
\hline Luís Alberto & & & & & & & 1 \\
\hline Erotides Borges & & & 1 & & 1 & 1 & \\
\hline Arquivaldo Bites & & & 1 & & & & \\
\hline Osmar de Lima & 2 & 1 & & & & & \\
\hline Luís C. Ferreira & & & 1 & & 1 & & \\
\hline Sebastião Leite & & 1 & & & & & \\
\hline Antonio Fonseca & & & 1 & & & & \\
\hline Ceser Donisete & 1 & & 2 & & & 1 & \\
\hline Vanilda A & & & & & & & 3 \\
\hline Oséas Porto S. & & & 1 & & & & \\
\hline Wilson Marcos & & & & & 1 & & \\
\hline Luís C. Bueno & & 1 & 1 & & & & \\
\hline Bianor Ferreira & & & & 1 & & & \\
\hline Neyde Aparecida & & & & & 2 & & \\
\hline Amarildo D. & & & & & & 1 & \\
\hline Laisy Moriére & & & & & & & 1 \\
\hline Dumar Prado & & & & 1 & & & \\
\hline Itamar Paes & & & & & & 2 & \\
\hline Antônio Macário & & 1 & & 1 & & & \\
\hline Sergio Alberto & & & & & 1 & & \\
\hline Senivaldo Silva & & & & & & & 2 \\
\hline Maria dos Santos & & & 1 & & & & \\
\hline Paulo César & & & & 1 & & & \\
\hline Carmem Síria & & & & & 1 & & \\
\hline $\begin{array}{l}\text { Madson } \\
\text { Rodrigues }\end{array}$ & & & & & & 1 & \\
\hline
\end{tabular}

Fonte: Diretório Estadual do PT. 
O quadro 1.4 apresenta a distribuição dos integrantes nas composições da Executiva Estadual do PT (1980-2017), por meio das seguintes instâncias: Presidente (8); $1^{\circ}$ Vice-Presidente (12); $2^{\underline{0}}$ Vice-Presidente (10); $3^{\text {o }}$ Vice-Presidente (4); Secretário Geral (10); 1 Secretário (10) e Tesoureiro (7). Alocação dos 43 integrantes, dentre as quatro variáveis: Estabilidade Baixa (24); Estabilidade Média (10); Estabilidade Alta (4); Oligarquização (5).

\section{O processo de renovação ou oligarquização das lideranças partidárias: o caso de}

\section{Goiás}

Os quatro quadros apresentados anteriormente possibilitaram um panorama mais geral de cada composição executiva dos quatro partidos, contendo os nomes de todos os integrantes, número de vezes que cada indivíduo exerceu uma ou mais funções, além da quantidade de integrantes em cada instância.

Nessa secção analisaremos cada Composição Executiva pelo fluxo das lideranças dentre as variáveis: a) Estabilidade Baixa, b) Estabilidade Média, c) Estabilidade Alta e d) Oligárquica, conforme quadro abaixo:

\section{Quadro 2.1 - Composições da Executiva Estadual por circulação das lideranças}

\begin{tabular}{|c|c|c|c|c|c|}
\hline Partidos/Frequência & A) Baixa & B) Media & C) Alta & D) Oligárquica & TOTAL \\
\hline PSDB & 28 & 14 & 1 & 4 & 47 \\
\hline PFL/DEM & 19 & 6 & 5 & 2 & 32 \\
\hline PMDB & 29 & 8 & 3 & 5 & 45 \\
\hline PT & 24 & 10 & 4 & 5 & 43 \\
\hline
\end{tabular}

Fonte: Diretórios estaduais de Goiás.

Segundo os dados do quadro 2.1, é possível notar que, de maneira geral, todos os quatro partidos possuem relativa circulação dos seus integrantes nas respectivas executivas, dado a predominância das variáveis a), b) e c). Dos 47 integrantes do PSDB, 43 estiveram na faixa de circulação e apenas 4 na faixa de oligarquização; no PFL/DEM, 
dos 32 integrantes, 30 estiveram na faixa de circulação e 2 na faixa oligárquica; já no PMDB, das 45 lideranças, 40 estiveram na faixa de circulação e 5 na faixa oligárquica e no PT, dos 43 ocupantes, 37 estiveram na zona de circulação. Preliminarmente, constatase nos quatro partidos a predominância da circulação em detrimento da oligarquização. Porém, isso não nos diz o número de instâncias e funções que a parte oligárquica ocupou em cada partido.

Nos próximos quatro quadros serão demonstradas as especificidades da faixa mais oligárquica de cada composição, com o nome dos ocupantes, função e número de vezes que exerceu cada função. O intuito é demonstrar a especificidade oligárquica de cada partido, se é mais horizontal, vertical, ou os dois. Além disso, elencar quais as funções mais oligarquizadas e, por último, fazer uma comparação entre o número exercido de atividades de todos os integrantes da faixa oligárquica, comparando-os com todos os integrantes na faixa de circulação

\section{Quadro 2.2 - Integrantes com maior participação na Executiva Estadual - PSDB}

\begin{tabular}{|c|c|c|c|c|}
\hline Funções/Integrantes & Paulo Silva & Edmundo D. & Antonio F. & Sergio $C$. \\
\hline Presidente & 2 & & 3 & \\
\hline 1 $^{\circ}$ Vice-Presidente & & 1 & 1 & \\
\hline $2^{\text {o }}$ Vice Presidente & & & & 1 \\
\hline $3^{\text {o Vice-Presidente }}$ & & & & \\
\hline Secretário-Geral & 1 & & & 3 \\
\hline 1o Secretário & 3 & & & \\
\hline Tesoureiro & 3 & 6 & 1 & \\
\hline Total & 9 & 7 & 5 & 4 \\
\hline
\end{tabular}

Fonte: Diretório Estadual do PSDB de Goiás.

No PSDB podemos notar que cada um dos 4 integrantes com mais funções na Executiva, exerceu no mínimo 4 e no máximo 9 cargos. A concentração em cada instância ficou da seguinte forma: Tesoureiro (10), Presidente (5), Secretário Geral (4), 1o Secretário (3), 1ํo Vice-Presidente (2), 2º Vice-Presidente (1) e $3^{\circ}$ Vice-Presidente (o). A 
oligarquização no PSDB possui uma característica horizontal, ou seja, a concentração das elites se dá por meio de acúmulo de atividades em instâncias diferentes.

\section{Quadro 2.3 - Integrantes com maior participação na Executiva Estadual - PFL/DEM}

\begin{tabular}{|c|c|c|}
\hline Funções/Integrantes & Ronaldo Caiado & Luiz C. Rates \\
\hline Presidente & 6 & \\
\hline $\mathbf{1}^{\mathbf{0}}$ Vice-Presidente & & \\
\hline $\mathbf{2}^{\mathbf{0}}$ Vice Presidente & & \\
\hline $3^{\mathbf{0}}$ Vice-Presidente & & \\
\hline Secretário-Geral & & \\
\hline $\mathbf{1}^{\mathbf{0}}$ Secretário & & 4 \\
\hline Tesoureiro & & \\
\hline Total & $\mathbf{6}$ & \\
\hline
\end{tabular}

Fonte: Diretório Estadual do DEM de Goiás.

Na Comissão Executiva Estadual do PFL/DEM é possível notar que cada um dos 2 componentes com maior acúmulo de atividades nas instâncias exerceu no mínimo $4 \mathrm{e}$ no máximo 6 funções. Os cargos mais ocupados pela soma dos 2 integrantes foram: Presidente (6) e Tesoureiro (4). Diferente do PSDB, no PFL/DEM a oligarquização ocorre de forma vertical, ou seja, por acúmulo de funções em uma mesma instância.

Quadro 2.4 - Integrantes com maior participação na Executiva Estadual - PMDB

\begin{tabular}{|c|c|c|c|c|c|}
\hline Funções/Integrantes & $\begin{array}{c}\text { Iris } \\
\text { Resende }\end{array}$ & $\begin{array}{c}\text { Adib } \\
\text { Elias }\end{array}$ & $\begin{array}{c}\text { Pedro } \\
\text { Chaves }\end{array}$ & $\begin{array}{c}\text { Nailton } \\
\text { Silva }\end{array}$ & $\begin{array}{c}\text { Francisco } \\
\text { Castro }\end{array}$ \\
\hline Presidente & 4 & $\mathbf{2}$ & & $\mathbf{2}$ & \\
\hline $\mathbf{1}^{\mathbf{0}}$ Vice-Presidente & & $\mathbf{1}$ & & $\mathbf{1}$ & \\
\hline $\mathbf{2}^{\mathbf{0}}$ Vice Presidente & & & 3 & 1 & \\
\hline $3^{\mathbf{0}}$ Vice-Presidente & & & & & 3 \\
\hline Secretário-Geral & & & 1 & & \\
\hline
\end{tabular}




\begin{tabular}{|c|c|c|c|c|c|}
\hline $1^{\circ}$ Secretário & & & & & 1 \\
\hline Tesoureiro & & 1 & & & \\
\hline Total & 4 & 4 & 4 & 4 & 4 \\
\hline
\end{tabular}

Fonte: Diretório Estadual do PMDB de Goiás.

No PMDB a oligarquização ocorre predominantemente de forma horizontal, com apenas um acúmulo vertical por Iris Resende. Há estabilidade entre o número de funções na elite do partido, com quatro funções para cada um dos cinco integrantes Os cargos mais ocupados foram: Presidente (8), Secretário Geral (4), 1o Vice-Presidente (2), 2o Vice-Presidente (4), o Secretário (1) e Tesoureiro (1).

\section{Quadro 2.5 - Integrantes com maior participação na Executiva Estadual - PT}

\begin{tabular}{|c|c|c|c|c|c|}
\hline Funções/Integrantes & $\begin{array}{c}\text { Valdi } \\
\text { Camarcio }\end{array}$ & $\begin{array}{l}\text { Athos } \\
\text { Pereira }\end{array}$ & $\begin{array}{l}\text { Athos } \\
\text { Magno }\end{array}$ & $\begin{array}{c}\text { Rubens } \\
\text { Otoni }\end{array}$ & $\begin{array}{c}\text { Ceser } \\
\text { Donisete }\end{array}$ \\
\hline Presidente & 3 & 1 & 3 & 3 & 1 \\
\hline 1ㅇ Vice-Presidente & 3 & 2 & & & \\
\hline 2 Vice Presidente $^{\circ}$ & & & & & 2 \\
\hline \multicolumn{6}{|l|}{ 3o Vice-Presidente } \\
\hline Secretário-Geral & & & 1 & 1 & \\
\hline $1^{\mathrm{o}}$ Secretário & & 1 & & & 1 \\
\hline Tesoureiro & & 1 & & & \\
\hline Total & 6 & 5 & 4 & 4 & 4 \\
\hline
\end{tabular}

Fonte: Diretório Estadual do PT de Goiás.

Já no Partido dos Trabalhadores, a oligarquização ocorre de forma predominantemente horizontal. A participação dos integrantes dentre as 7 instâncias têm maior peso. A soma das instâncias mais oligarquizadas é: Presidente (11), o VicePresidente (5), Tesoureiro (1), 1o Secretário (2), Secretário Geral (2), 2º Vice-Presidente (2).

Por fim, o quadro 2.6 irá demonstrar, dentre as faixas oligárquicas de cada partido, o grau de concentração em cada uma delas. O intuito é comparar o número de 
funções em que as elites dos partidos ou a variável (d) Oligárquica exerceu em detrimento dos outros integrantes que fazem parte das variáveis (a), (b) e (c).

\section{Quadro 2.6 - Funções exercidas por variável}

\begin{tabular}{|c|c|c|c|c|c|}
\hline Funções/Variável & $\begin{array}{c}\text { Comissão } \\
\text { Executiva }\end{array}$ & $\begin{array}{c}\text { A) } \\
\text { Baixa }\end{array}$ & $\begin{array}{c}\text { B) } \\
\text { Média }\end{array}$ & $\begin{array}{c}\text { C) } \\
\text { Alta }\end{array}$ & D) Oligárquica \\
\hline PSDB & 47 & 28 & 28 & 3 & 25 \\
\hline PFL/DEM & 32 & 19 & 12 & 15 & 10 \\
\hline PMDB & 45 & 29 & 16 & 9 & 20 \\
\hline PT & 43 & 24 & 20 & 12 & 23 \\
\hline
\end{tabular}

Fonte: Diretórios Estaduais.

Os dados do quadro 2.6 indicam que os partidos com maior concentração de funções das elites por faixa oligárquica foram: 1) PSDB (25), 2) PT (23), 3) PMDB (20) e 4) PFL/DEM (10).

Contudo, utilizando-se da comparação entre o número de funções exercidas pela faixa oligárquica em comparação com cada uma das três faixas de estabilidade ou circulação, veremos outro resultado. Para isso, utilizamos do seguinte raciocínio: quanto mais o número de funções na variável d) se aproximar do total de funções de cada uma das variáveis a), b) e c), maior será o nível de oligarquização. Desse modo, chegamos ao seguinte resultado: 1) PT, 2) PMDB, 3) PSDB e 4) PFL/DEM. No PT, a variável d) ultrapassa c), b) e quase iguala a a); quando passamos ao PMDB, a variável d) ultrapassa c) e b) e fica mais distante de a); no PSDB é onde se encontra o maior equilíbrio entre circulação e oligarquização. Nesse partido, a variável d) ultrapassa, e muito, a variável c), mas se aproxima de b) e a); já no PFL/DEM há o inverso. A variável d) não ultrapassa c) e b), nem se aproxima de a).

\section{Considerações finais}

O resultado da pesquisa confirmou que em todos os quatro partidos pesquisados (PMDB, PFL/DEM, PT e PSDB), na Comissão Executiva, há mais circulação das 
lideranças que oligarquização. No entanto, em todos há um grau de oligarquização que pode ser mais horizontal, quando ocorre a concentração em mais de uma função, ou vertical, quando essa ocorre no acúmulo de funções na mesma instância, ou mista. No espectro ideológico, Esquerda, Centro e Direita, o partido com maior concentração oligárquica se encontra no espectro Esquerda (PT) e Centro (PMDB). Cabe ressaltar que as eleições diretas para a composição da Executiva Estadual do PT só começaram a ocorrer a partir de 2001. No PFL, entre 1998 e 2006 não foi encontrado nas atas e documentos eleições nesse período, mas somente menções ao presidente Ronaldo Caiado. Essas duas observações podem ter tido influência decisiva nos resultados aqui encontrados.

Com exceção do PT que, por vinte anos elegeu a sua Executiva Estadual de forma indireta, todos os demais partidos possuíram eleições de forma periódica, com ressalva ao PFL, que preferimos ficar na hipótese de que entre os anos de 1998 e 2006 não houve eleições para composição da Comissão Executiva Estadual.

Os estudos sobre a organização interna dos partidos políticos impõem ainda muitos desafios aos cientistas sociais. Para a consulta aos dados mais antigos da composição de cada executiva, o pesquisador fica a mercê daquilo que consegue extrair dos livros de atas e registro, exigindo um trabalho de lupa, já que, na maioria das vezes, as composições são encontradas junto a outras informações mais gerais do partido. Dos quatro partidos, apenas o PT disponibilizou as composições de sua Comissão Executiva por meio de um documento eletrônico. Os partidos em geral não possuem arquivos digitalizados e o Tribunal Regional Eleitoral (TRE) disponibiliza um banco de dados com informações a partir do ano de 2000. Essa base de dados do TRE foi decisiva para a montagem da Comissão Executiva do DEMOCRATAS, já que no diretório desse partido só foi possível coletar informações em atas do período do extinto PFL. A ata com a composição do Democratas não estava disponível no diretório e não foi possível precisar com a secretaria do partido onde ela poderia estar.

\section{Referências}

AMARAL, Oswaldo E. Revista Debates, Porto Alegre, v. 7, n. 2, p. 11-32, maio-ago. 2013. 
BOBBIO, Norberto; MATTEUCCI, Nicola; PASQUINO, Gianfranco. Dicionário de Política. 13. ed. Brasília: UNB, 2007.

BOHN, S. R; PAIVA FERREIRA. A volatilidade eleitoral nos estados, sistema partidário e democracia no Brasil. Revista Sociologia e Política (UFPR. Impresso), v. 17, p. 187208, 2009.

BRAGA, Maria do Socorro. Revista Sociologia e Política, Curitiba, n. 44, p. 84-05, nov. 2012.

COUTO, C. G. 2010. Oligarquia e processos de oligarquização: um problema institucional das organizações. Artigo apresentado no VII Encontro da Associação Brasileira de Ciência Política, realizado em Recife (Pernambuco), de 4 a 7 de agosto

DEMOCRATAS (BRASIL). In: WIKIPÉDIA, a enciclopédia livre. Flórida: Wikimedia Foundation, 2020. Disponível em: $<$ https://pt.wikipedia.org/w/index.php?title=Democratas_(Brasil)\&oldid=58242349>. Acesso em: 03 jun. 2020.

DUVERGER, M. 1987. Os partidos políticos. Rio de Janeiro: Guanabara.

GIMENES, Éder R. Teoria das elites e as elites do poder: considerações sobre a relevância dos teóricos e de Whight Mills aos estudos de cultura política e democracia. Revista de Discentes de Ciência Política da UFSCAR, v. 2, n. 2, 2014.

GUNTHER, Richard; DIAMOND, Larry. Espécies de partidos políticos: uma nova tipologia. In: Paraná Eleitoral: Revista Brasileira de direito eleitoral e Ciência Política. Curitiba: TRE-PR, v. 4, n. 1, p. 7-51, 2015.

KIRCHHEIMER, Otto. The Transformation of the Western European Party Systems. In: LAPALOMBARA, Joseph; WEINER, Myron (ed.) Political Parties and Political Development. Princeton: PUP, 1966. P. 177-200.

KRAUSE, S. Governadores na "era PMDB" em Goiás (1982 - 1998): um caso de hiperpresidencialismo? In: PAIVA FERREIRA, D e Bezerra, H. D. (org) (20o8). Panorama da política em Goiás. Goiânia, Ed. PUC Goiás.

MAINWARING, Scott. Sistemas Partidários em novas democracias: o caso do Brasil. Rio de Janeiro: FGV, 2001.

MAIR, Peter. Partidos Políticos e a democracia. In: Análise social. v. 167, p. 277-293, 2003.

MEDDING, P. Y. 1970. A Framework for the Analysis of Power in Political Parties. Political Studies, Malden, v. 18, n. 1, p. 1-17, mar. 
MELO, Carlos Ranulfo; ALCANTARA SAEZ, Manuel. A Democracia brasileira: balanço e perspectivas para o século XXI. Belo Horizonte: Ed. UFMG, 2007.

MICHELS, Robert. A Sociologia dos Partidos Políticos. Brasília: Editora Universidade de Brasília, 1982.

MIGUEL, Luis Felipe. A democracia domesticada: bases antidemocráticas do pensamento democrático contemporâneo. DADOS Revista de Ciências Sociais, Rio de Janeiro, vol. 45, n. 3, 2002, p. 483 a 511.

MOVIMENTO DEMOCRÁTICO BRASILEIRO (1980). In: WIKIPÉDIA, a enciclopédia livre. Flórida: Wikimedia Foundation, 2020. Disponível em: $<$ https://pt.wikipedia.org/w/index.php?title=Movimento_Democr\%C3\%Artico_Brasilei ro_(1980)\&oldid=58385930 $>$. Acesso em: 3 jun. 2020.

OSTROGORSKI, M. J. 1970. Democracy and the Organization of Political Parties. New

York: Haskell.

PAIVA FERREIRA, D. e Bezerra, H. D. (org.) (2008). Panorama da Política em Goiás. Goiânia, Ed. PUC Goiás.

PAIVA FERREIRA, D.; PIETRAFESA, Pedro Araújo. Política Partidária e Competição Eleitoral em Goiás: Goiânia, 2013.

PANEBIANCO, Angelo. Modelos de partido: organização e poder nos partidos políticos. São Paulo: Martins Fontes, 2005.

PARTIDO DOS TRABALHADORES. In: WIKIPÉDIA, a enciclopédia livre. Flórida: Wikimedia Foundation, 2020. Disponível em: $<$ https://pt.wikipedia.org/w/index.php?title=Partido_dos_Trabalhadores\&oldid=583515 25>. Acesso em: 03 jun. 2020.

PERISSINOTO, Renato. As Elites Políticas: questões de teoria e método. Curitiba: IBPEX, 2009. 